\title{
沈降場流動分画法による粒子径測定における溶離液の影響
}

\author{
森康 維*, 原田雅 浩*, 宮本 慶一* \\ 井上真 司**, 鈴木 幹彦**, 谷垣 昌 敬**
}

\section{The Effect of a Carrier Solution on Particle Size Measurement by Sedimentation Field-flow Fractionation}

by

\author{
Yasushige MORI $^{\dagger}$, Masahiro HARADA $^{\dagger}$, Keiichi MIYAMOTO $^{\dagger}$ \\ Sinji INOUE ${ }^{\dagger \dagger}$, Mikihiko SUZUKI ${ }^{\dagger \dagger}$ and Masataka TANIGAKI ${ }^{\dagger \dagger}$
}

\begin{abstract}
In order to analyze the size distribution of sub-micron particles by the sedimentation field-flow fractionation, a new apparatus which includes a rotary joint consisting of a flat surface seal and a rotary column with changeable wall material and channel thickness was coustructed.

At a low ionic strength in the aqueous carrier solution, the elution time of particles in sedimentation field-flow fractionation deviates from that by Giddings' theory, resulting in underestimation of the particle size. In this case, the elution time of particles can better be estimated by considering the particle-wall interaction and the fluid force effect. In the methanol carrier solution, the behavior of particles is apparently the same as that in the aqueous carrier solution. The particle size could be estimated by Giddings' theory when the aqueous or methanol solution with a certain concentration of di-2ethylhexyl sodium sulfosuccinate(Aerosol OT) surfactant was used as a carrier solution.
\end{abstract}

Key Words : Field-flow Fractionation, Particle Size Measurement,

Liquid Chromatography, DLVO Theory, Separation by Flow

\section{1. 緒言}

流動分画(FFF)法は，コロイド粒子を外力の作用し たカラム内で粒子径別に分離・分画する方法で, 一相 クロマトグラフィーに分類される分析手法である ${ }^{1 \sim 4)}$ 。 沈降場流動分画(SdFFF) 法は, 遠心力を外力として

\section{5年 3) 27 日受付}

第32回粉’:に関する討論会(1994年10月，つくば)にて発表

* 同志社 大学工学部物質化学工学科

( $=611-03$ 京都府緅喜郡田辺町多々羅都谷 1の3)

TEL. $3774-65-6626$

** 京都; 学工学部化学工学教室

( ₹61 ;-01 京都市左京区吉田本町)TEL. 075-753-5566

$\dagger$ Dept of Chem. Eng. and Mater. Sci., Doshisha Univ., (Ta) ibe-cho, Kyoto 610-03)

t† Dep of Chem. Eng., Kyoto Univ.,

(Sa yo-ku, Kyoto 606-01)
用いるFFF法の一つであり，サブミクロン粒子の粒子 径測定に適している。粒子の溶離挙動(流出時間)から 粒子径を算出する理論的根拠は, J. ‘. Giddings $5^{5-7)}$ によって提出された。この式では, 粒子と液体(溶離 液) との密度差, 流速, 遠心力およびカラムの大きさ のみが変数であり, 実験值とよく一致することが報告 されてきた。しかし近年, 使用する溶離液の条件によ っては, Giddingsの式との一致が悪く, 粒子と装置壁 との相互作用, 粒子間の相互作用や試料の過負荷を考 慮する必要が指摘されている ${ }^{8-13)}$ 。

本研究では, SdFFF法に基づく装置を試作し，標準 ポリスチレンラテックス(PSL)粒子と, イオン性界面 活性剂を含む蒸留水やメ夕ノ一ルを溶離液に用いて, その性能を評価した。さらにDLVO理論に基づく粒子 
と装置壁との相互作用力，および剪断流れ場において 粒子に働く流体力を考慮した粒子の溶離挙動の計算を 行い, 実験結果と比較検討した。

\section{2. 理 論}

Giddingsらによれば，粒子の流出時間と溶離液の平 均滞留時間との比で表現される保持比は次式とな $3^{6)}$ 。

$$
\begin{aligned}
R= & \frac{t_{0}}{t_{\mathrm{p}}}=6 \alpha(1-\alpha) \\
& +6 \lambda(1-2 \alpha)\left[\operatorname{coth}\left(\frac{1-2 \alpha}{2 \lambda}\right)-\frac{2 \lambda}{1-2 \alpha}\right]
\end{aligned}
$$

ここで $\lambda=6 k T /\left(\pi \Delta \rho d_{\mathrm{p}}^{3} G w\right), \alpha=d_{\mathrm{p}} /(2 w)$ である。

水溶液中で異種物質が数 $\mu \mathrm{m}$ 内に近づくと, コロイ ド力が発生する ${ }^{14,15)}$ 。そこで筆者らはSdFFF装置の 壁近傍の粒子に対しても，DLVO理論に基づく London-van der Waals引力と, 静電気反発力が働く と考え，保持比に及ぼすコロイドカの影響を検討し た9)。

さらに平板近傍における剪断流れ場における粒子の 運動についてのGoldman ら ${ }^{16)}$ の研究結果を用いて, 粒 子が粒子中心位置の流体とは異なった移動速度をとる こと(流体力)を考慮した保持比の計算手法を提出し た ${ }^{13)}$ 。

コロイド力と流体力を考慮した計算手法では, 保持 比の解析解は得られず, 次式のようなチャネルの厚さ 方向 $(x$ 方向)の空間平均を求める必要がある。

$$
R=\frac{t_{0}}{t_{\mathrm{p}}}=\frac{\left\langle v_{\mathrm{p}}(x) c(x)\right\rangle}{u_{\mathrm{m}}\langle c(x)\rangle}
$$

ここで装置壁からチャネルの厚さ方向に $x$ だ離れた 点における溶離液の流れ方向の粒子移動速度は, Goldmanらの研究結果 ${ }^{16)}$ 修正した次式で求まる。

$$
\begin{array}{rl}
\frac{v_{\mathrm{p}}(x)}{u(x)}=1-0.32\left(\frac{d_{\mathrm{p}}}{2 x}\right)^{3} & 0.57 \leq \frac{x}{d_{\mathrm{p}}} \\
=\frac{0.809}{0.6376-0.2 \ln \left(\frac{2 x-d_{\mathrm{p}}}{d_{\mathrm{p}}}\right)} & 0.5<\frac{x}{d_{\mathrm{p}}} \leq 0.57
\end{array}
$$

$u(x)$ は無限平行平板間を層流で流れるとした場合の 溶離液の流速である。

さらにその点における粒子の濃度は, 次の微分方程 式の解である。

$$
\frac{\mathrm{d} c(x)}{\mathrm{d} x}+\left(\frac{1}{\lambda w}+\frac{\mathrm{d} V_{\mathrm{pw}}(x)}{\mathrm{d} x}\right) \cdot c(x)=0
$$

Eq. (4) 中の粒子・装置壁間の相互作用エネルギ一は, van der Waals 相互作用 $V_{\mathrm{pw}, \mathrm{A}}$ と静電相互作用 $V_{\mathrm{pw}, \mathrm{R}}$ の 和として表現できる。

$V_{\mathrm{pw}}(x)=V_{\mathrm{pw}, \mathrm{A}}(x)+V_{\mathrm{pw}, \mathrm{R}}(x)$

$V_{\mathrm{pw}, \mathrm{A}}(x)=-\frac{A_{123}}{6}\left\{\frac{d_{\mathrm{p}}}{2 x-d_{\mathrm{p}}}+\frac{d_{\mathrm{p}}}{2 x+d_{\mathrm{p}}}+\ln \left(\frac{2 x-d_{\mathrm{p}}}{2 x+d_{\mathrm{p}}}\right)\right\}$

$\kappa d_{\mathrm{p}} \gg 1$ では

$$
\begin{aligned}
V_{\mathrm{pw}, \mathrm{R}}(x)= & \frac{32 \pi \varepsilon_{0} \varepsilon_{\mathrm{f}} d_{\mathrm{p}} k^{2} T^{2} \Psi_{\mathrm{p}} \Psi_{\mathrm{w}}}{e_{0}^{2}} \\
& \times \ln \left[1+\exp \left\{-\kappa\left(x-\frac{d_{\mathrm{p}}}{2}\right)\right\}\right]
\end{aligned}
$$

$\kappa d_{\mathrm{p}} \ll 1$ では

$$
\begin{aligned}
V_{\mathrm{pw}, \mathrm{R}}(x)= & \frac{128 \pi \varepsilon_{0} \varepsilon_{\mathrm{f}} k^{2} T^{2} \Psi_{\mathrm{p}} \Psi_{\mathrm{w}}}{e_{0}^{2}} \cdot \frac{d_{\mathrm{p}} x}{2 x+d_{\mathrm{p}}} \\
& \times \ln \left[1+\frac{d_{\mathrm{p}}}{2 x} \exp \left\{-\kappa\left(x-\frac{d_{\mathrm{p}}}{2}\right)\right\}\right] \\
\text { ここで } \kappa^{2}= & \frac{2 e_{0}^{2} N_{\mathrm{A}} I}{\varepsilon_{0} \varepsilon_{\mathrm{f}} k T}, \quad \Psi_{\mathrm{p}}=\tanh \left(\frac{e_{0} \phi_{\mathrm{p}}}{4 k T}\right), \\
\Psi_{\mathrm{w}}= & \tanh \left(\frac{e_{0} \phi_{\mathrm{w}}}{4 k T}\right)
\end{aligned}
$$

溶離液を介した粒子と壁との間のHamaker定数 $A_{123}$ を必要とするが, 次式から計算できる14)。

$$
A_{123}=\left(\sqrt{A_{11}}-\sqrt{A_{33}}\right)\left(\sqrt{A_{22}}-\sqrt{A_{33}}\right)
$$

ここで $A_{11}$ は粒子の, $A_{22}$ は装置壁の, $A_{33}$ は溶離液の Hamaker定数であり, Table 1 のうな值を採用し た。 $A_{33}$ は松本ら ${ }^{17)}$ の, $A_{11}$ はCroucher ${ }^{18)}$ の報告から 引用した。 $A_{22}$ は, Hansen ら ${ }^{11)}$ の論文中の $A_{223}$ の值, Table 1 の $A_{33}$ の值およびEq.(9)から求めた。

また表面電位

Table 1 Hamaker constants and $\zeta$-potential used in calculation

\begin{tabular}{clr}
\hline$A_{11}$ & PSL & $9.8 \times 10^{-20} \mathrm{~J}$ \\
$A_{22}$ & stainless steel & $2.26 \times 10^{-19} \mathrm{~J}$ \\
$A_{33}$ & $\left\{\begin{array}{lr}\text { water } \\
\text { methanol }\end{array}\right.$ & $\begin{array}{c}4.77 \times 10^{-20} \mathrm{~J} \\
\end{array}$ \\
\hline$\zeta_{\mathrm{w}}$ & stainless steel & $-18 \mathrm{mV}$ \\
$\zeta_{\mathrm{p}}$ & $\{$ PSL in water & $-54 \mathrm{mV}$ \\
& PSL in methanol & $-77 \mathrm{mV}$ \\
\hline
\end{tabular}


るら電位の値で代用する。Table 1 に顕微鏡電気泳動 法による粒子のら電位測定值を示す。装置壁(ステン レススチール)のら電位も示すが, 流動電位測定装置 を用いて測定したステンレススチール粉のら電位を採 用した。

\section{3. 実験装置}

Fig. 1 にSdFFF法の装置の概略を示す。装置は, ポンプ(島津製作所製，LC-6A)，試料注入部 (Rheodyne製，7725)，遠心機(トミ一精工製，RLX9200 相当品)，紫外可視吸光光度計(島津製作所製, SPD-6A)，天科(エー・アンド・ディ製，FA-2000） およびパーソナルコンピュータから成っている。分離 部本体は, 遠心機内の回転力ラム $($ 回転直径 $20 \mathrm{~cm})$ に 設置された幅 $2 \mathrm{~cm}$ ，長さ約 $60 \mathrm{~cm}$ の矩形断面のチャネ

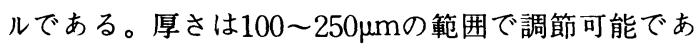
る。チャネルの壁は鏡面仕上げのステンレススチール である。溶離液の流出入のために，平面接触型の回転 面シール(回転ジョイント)を採用している。回転数の 制御は装置本体での設定の他に, 外部電圧入力設定も 可能な仕様を備えている。紫外可視吸光光度計の吸光 度, 天秤で測定している流出液重量および遠心機の回 転数は, 試料導入後, パーソナルコンピュータに測定 データとして一定時間間隔毎に記録される。

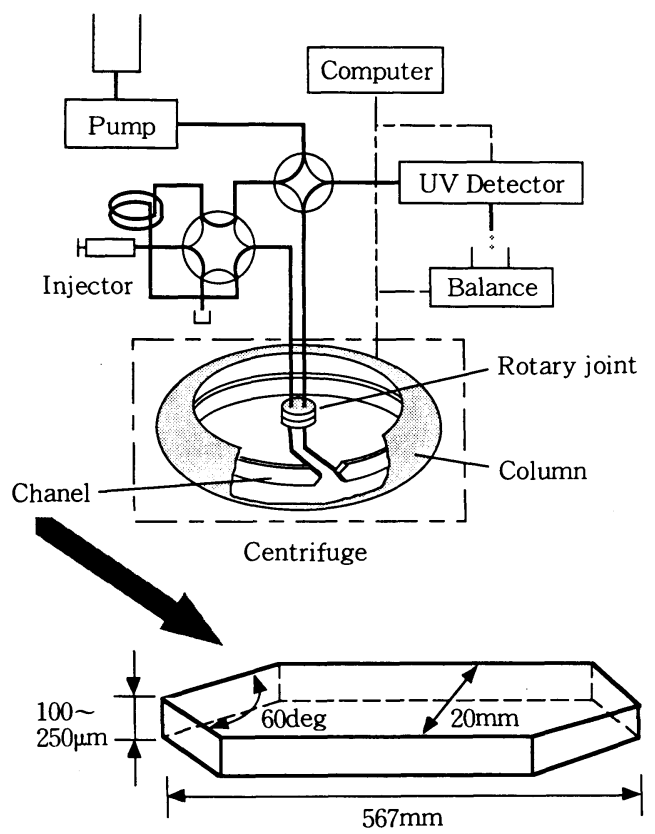

Fig. 1 Schematic diagram of sedimentation field-flow fractionation and channel dimension
蒸留水または市販特級のメタノールを公称径 $0.1 \mu \mathrm{m}$ のフイルターで滤過し，15分間以上減圧下で超音波脱 気した液を溶離液とした。濃度 $0.04 \mathrm{wt} \%$ のラテック ス(PSL) 標準粒子(日本合成ゴム製, STADEX)を試 料とした。

回転カラム内のチャネルに溶離液を流し, 送液ポン プ, 遠心機及び検出器が安定に作動していることを確 認後，実験を開始する。送液量を $1 \mathrm{ml} / \mathrm{min}$, 試料導入 時間を 5 秒とした。その後，流路切り換え用四方バル ブを操作し，回転カラム内の流れを止め，チャネル内 に粒子径に对応した粒子濃度分布を形成させる。この 期間は楥和期間と呼ばれ, FFF法特有の操作であ る。緩和期間終了後, 再び回転カラム内に所定流量で 溶離液を流し，測定を開始する。

\section{4. 実験結果および考察}

\section{1 溶離液が水溶液の場合}

Fig. 2に分光光度計で測定された吸光度の経時変化 の一例を示す。横軸の時間は試料導入時から数えてい る。このため 5 秒の試料導入期間と 3 分の緩和期間の 終了後, 流路切り換えバルブ操作のノイズ, ボイドピ 一クと呼ぶ溶離液の平均滞留時間に相当するピークが 現れている。続いて粒子径の小さい粒子の流出ピーク が出現し，その後粒子径の大きい粒子が流出する。し かし溶離液に蒸留水を用いた場合と, $0.1 \mathrm{~mol} / \mathrm{m}^{3}$ のラ ウリル硫酸ナトリウム(SDS) 陰イオン性界面活性剂 水溶液を用いた場合では粒子の流出時間が異なってい る。このように水にイオン性界面活性郕を添加するだ けで，粒子の流出特性が異なる理由の一つに，水溶液

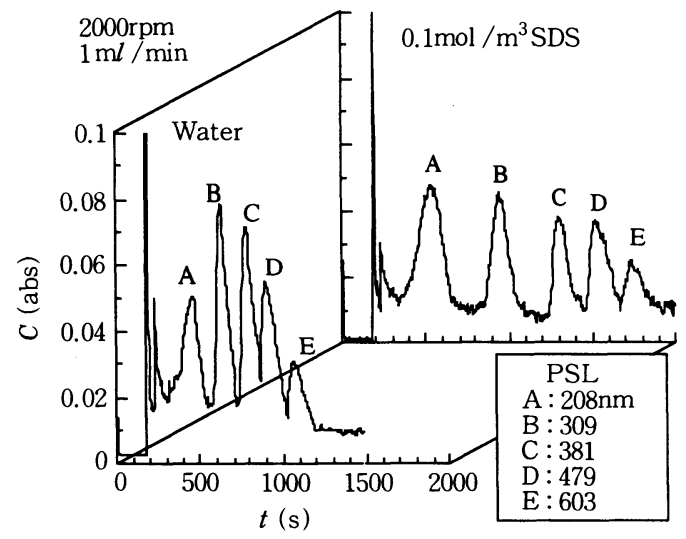

Fig. 2 Fractogram of polystyrene latex(PSL) particles in sedimentation field-flow fractionation with water or sodium dodecylbenzene sulfonate(SDS) solution 


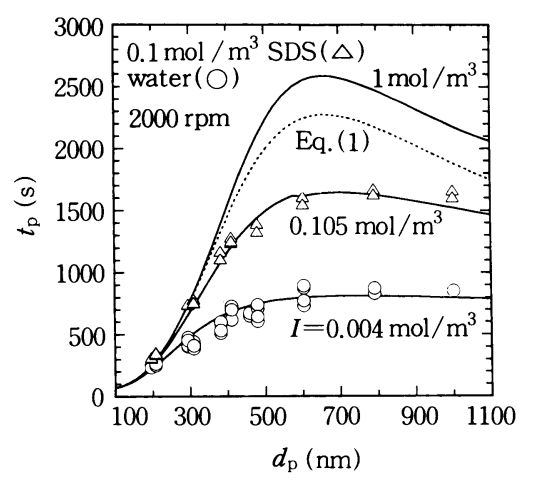

Fig. 3 Comparison of observed and calculated elution time of particles with aqueous solution. Broken line and solid lines, respectively, are calculated by Eq. (1) and Eq. (2)

のイオン強度に対応するコロイドカの影響が考えられ る。

各粒子の最大吸光度を示す時間を粒子流出時間と し，粒子流出時間と粒子径の関係をFig. 3に示す。実 験結果とGiddingsらの計算 $($ Eq. (1)) との一致は良く ない。 $0.1 \mathrm{~mol} / \mathrm{m}^{3} \mathrm{SDS}$ 水溶液のイオン強度は, 添加 したSDSの量と水素イオン濃度の実測值 $(\mathrm{pH}=5.3)$ か ら, $0.105 \mathrm{~mol} / \mathrm{m}^{3}$ と考えられる。また蒸留水の場合 は, 水素イオン濃度の実測值 $(\mathrm{pH}=5.4)$ から, イオン 強度を $0.004 \mathrm{~mol} / \mathrm{m}^{3}$ とした。これらのイオン強度に 基づいて, Eqs. (2)〜 (9)を用いた計算値を示す。測定 した全粒子径範囲で，実験值と計算值は良好な一致を 示している。また理論計算式でイオン強度を $1 \mathrm{~mol} /$ $\mathrm{m}^{3}$ にすると, 粒子径の大きい範囲ではEq. (1)を越え るが，ほぼ同様な流出時間を示すと考えられる。

Du Pont社のSdFFF法装置を用いた粒子径測定の 報告 ${ }^{19)}$ で, Kirklandらは溶離液として $2.25 \mathrm{~mol} / \mathrm{m}^{3}$ ス ルホこはく酸ナトリウム(AOT)陰イオン性界面活性 郕水溶液を推奨し, 実験的補正をEq. (1)に加えると, 粒子流出時間から粒子径への変換が可能であるとして いる。そこでチャネル幅と溶離液流量および溶離液組 成をKirklandらの報告に合わせて実験した。Fig. 4 に，遠心機の回転数を $1000 ， 1500,2000 \mathrm{rpm}$ と変えた 実験結果とEq.(1)の計算結果を示す。粒子径が600 $\mathrm{nm}$ 程度まではほぼ計算結果と一致している。このこ とは適当な溶離液を用いると, 複雜な計算をせずに Eq. (1)で粒子流出時間から粒子径を推定できること を示している。

\section{2 溶離液がメタノール溶液の場合}

Fig. 5に溶離液をメタノール溶液にした場合を示 す。メタノールのみの場合, 粒子径が大きくなっても

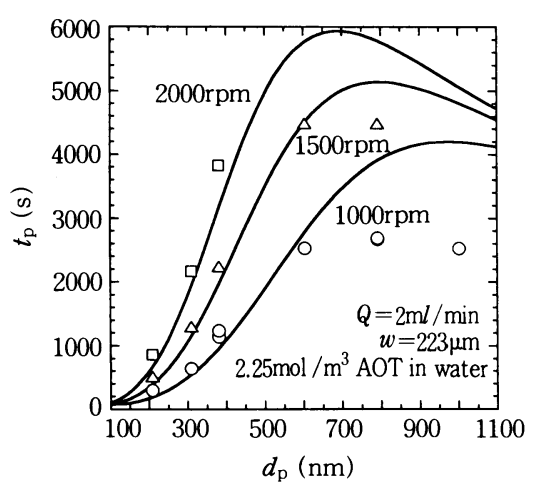

Fig. 4 Effect of centrifugal force on elution time of particles with $2.25 \mathrm{~mol} / \mathrm{m}^{3}$ di-2-ethylhexyl sodium sulfosuccinate (AOT) solution. Solid lines are calculated by Eq. (1)

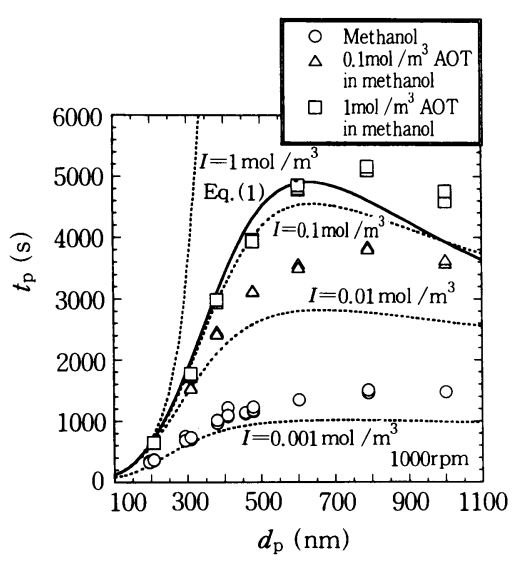

Fig. 5 Relationship between elution time of particles and size using methanol with various di-2ethylhexyl sodium sulfosuccinate (AOT) concentration as a carrier solution

粒子流出時間は大きくならず, 純水を溶離液にした場 合と良く似た挙動であり，Eq.(1)で粒子流出時間を子 測できないことが分かる。しかしメタノールにAOT を添加すると, 粒子流出時間は粒子径と共に大きくな ク, $1 \mathrm{~mol} / \mathrm{m}^{3}$ を含むメタノール溶離液では, 粒子径の 大きい範囲を除いて, 実験值はEq.(1)の計算值と一致 する。

Eq. (2)の計算では, メタノール溶液中でのイオン濃 度を知る必要があるが, 単にHamaker定数と比誘電 率をメタノールの值に変え, イオン強度を 0.001 か 1 $\mathrm{mol} / \mathrm{m}^{3}$ として計算した結果を図に示す。純メタノ一 ルではイオン強度を $0.001 \mathrm{~mol} / \mathrm{m}^{3}$ とした計算線とほ ぼ一致している。本実験で使用したメタノール中の含 水量は $50 \mathrm{~mol} / \mathrm{m}^{3}$ であり, 計算に用いたイオン強度の 
50,000倍に相当するので, メ夕ノ一ル中で水がわずか に解離すると考えれば妥当であると言える。しかし粒 子表面は親水性であることから, 粒子は水を吸着しや すく, 粒子表面近傍の水濃度はメ夕ノール中の平均よ り高いと考えられ, どの程度のイオン強度を採用する のが妥当であるかは今後の検討課題であろう。また AOTを添加した溶離液の場合も, イオン強度をAOT 漛度とすると計算值の方が, 実測值より大きくなり, AOT分子がすべて解離しているとは言えないようで ある。

\section{5. 結 論}

沈降場流動分画法に基づく装置を試作し，ポリスチ レンラテックス粒子と, イオン性界面活性剂を含む蒸 留水やメ夕ノ一ルを溶離液に用いて, その性能を評価 し, 以下の結論を得た。

1）低イオン強度の水溶液を溶離液に用いると,
Giddingsらの提案した式(Eq. (1))では実験值を予測 できず, DLVO理論に基づく粒子・壁間の相互作用を 考虑し, 壁近傍での粒子と流体との相互作用を考虑し た計算式(Eqs. (2)〜 (9))を用いる必要がある。

2）溶離液にメ夕ノール溶液を用いても, 粒子流出 挙動は水溶液とあまり変わらない。適当なイオン強度 の值を用いると, Eqs. (2)〜 (9) で実験值を説明できる。

3） $2.25 \mathrm{~mol} / \mathrm{m}^{3} \mathrm{AOT}$ 水溶液や $1 \mathrm{~mol} / \mathrm{m}^{3} \mathrm{AOT} \times タ$ ノ一ル溶液を溶離液とすると, 粒子流出時間と粒子径 の関係は, Eq.(1)でほぼ表現できる。

[謝辞] 本研究を行うにあたり, 財団法人ホソカ ワ粉体工学振興財団の助成金の援助を得ました。また 沈降場流動画化法装置の試作には, 日本電子株式会社 の竹内誠, 水野息夫両氏および株式会社卜ミ一精工の 絶大なる御協力を得ました。ここに記して謝意を表し ます。

\section{Nomenclature}

A : Hamaker constant

$c$ : particle concentration

$d_{\mathrm{p}}$ : particle diameter

$e_{0}$ : electronic charge

$G$ : field strength of centrifugal force

$k \quad$ : Boltzmann constant

$I \quad$ : ionic strength

$N_{\mathrm{A}}$ : Avogadro's constant

$Q$ : flow rate of carrier solution

$R \quad$ : retention ratio of particle

$T$ : absolute temperature

$t_{0}$ : elution time for a non-retained peak or average residence time of carrier solution (s)

$t_{\mathrm{p}}$ : elution time of particles or average residence time of particles

$u \quad$ : velocity of carrier solution

$u_{\mathrm{m}}$ : average velocity of carrier solution $\left(\mathrm{m} \cdot \mathrm{s}^{-1}\right)$ $\left(\mathrm{mol} \cdot \mathrm{m}^{-3}\right)$

(m)

$\left(\mathrm{m} \cdot \mathrm{s}^{-2}\right)$

$\left(\mathrm{J} \cdot \mathrm{K}^{-1}\right)$ $\left(\mathrm{mol} \cdot \mathrm{m}^{-3}\right)$

$\left(\mathrm{mol}^{-1}\right)$

$\left(\mathrm{m}^{3} \cdot \mathrm{s}^{-1}\right)$ $\left(\mathrm{m} \cdot \mathrm{s}^{-1}\right)$
$V_{\mathrm{pw}}:$ total free energy of interaction between particle and channel wall

$V_{\mathrm{pw}, \mathrm{A}}$ : van der Waals interaction free energy between particle and channel wall

$V_{\mathrm{pw}, \mathrm{R}}$ : electrostatic interaction free energy between particle and channel wall

$v_{\mathrm{p}}:$ velocity of particle $\quad\left(\mathrm{m} \cdot \mathrm{s}^{-1}\right)$

$w$ : channel thickness (m)

$\Delta \rho$ : density difference between particles and carrier solution $\quad\left(\mathrm{kg} \cdot \mathrm{m}^{-3}\right)$

$\varepsilon_{0} \quad$ : permittivity of free space $\quad\left(\mathrm{C}^{2} \cdot \mathrm{J}^{-1} \cdot \mathrm{m}^{-1}\right)$

$\varepsilon_{\mathrm{f}} \quad$ : relative permittivity of carrier solution (-)

$\zeta_{\mathrm{p}}: \zeta$ potential of particles

$\zeta_{\mathrm{w}}: \zeta$ potential of channel wall

$k \quad$ : inverse Debye length

$\phi_{\mathrm{p}} \quad$ : electrostatic surface potential of particles $(\mathrm{V})$

$\phi_{\mathrm{w}}$ : electrostatic surface potential of channel wall

\section{References}

1) Caldwell, K. D. : "Modern Methods of Particle Size Analysis(Ed. H. G. Barth)", p.211, John Wiley \& Sons Inc. (1984)

2) Giddings, J. C. : Sep. Sci., 1, 123(1966)

3) Janca, J. : “Field-Flow Fractionation”, Marcel Dekker (1987)

4) Funtai Kougakukai(Ed.) : "Ryuusi-kei Keisoku Gijutsu”, p.263, Nikkan Kogyo Shinbunsha(1994)

5) Giddings, J. C. : J. Chem. Phys., 49, 81(1968)

6) Giddings, J. C. : Sep. Sci. Technol., 13, 241(1978)

7) Hovingh, M. E., G. H. Thompson and J. C. Giddings : Anal. Chem., 42, 195(1970)
8) Mori, Y., B. Scarlett and H. G. Merkus : $J$. Chromatogr., 515, 27(1990)

9) Mori, Y. K. Kimura and M. Tanigaki : Anal. Chem., 62, 2668(1990)

10) Hoshino, T., M. Suzuki, K. Ysukawa and M. Takeuchi : J. Chromatogr., 400, 361(1987)

11) Hansen, M. E. and J. C. Giddings : Anal. Chem., 61, 811(1989)

12) Hansen, M. E., J. C. Giddings and R. Beckett : J. Colloid Interface Sci., 132, 300(1989)

13) Mori, Y. : Adv. Colloid Interface Sci., 53, 129 (1994) 
14) Kitahara, Y. and A. Watanabe : "Kaimen Denki Gensyou”, Kyouritsu Shuppan(1972)

15) Verwey, E. J. W and J. T. G. Overbeek :

"Theory of the Stability of Lyophobic Colloid", Elsevier (1948)

16) Matsumoto, M., A. G. Gaonkar and T.

Takenaka : Bull. Inst. Chem. Res., Kyoto Univ., 58,
523(1980)

17) Croucher, M. D. and M. L. Hair : J. Phys. Chem., 81, 1631(1977)

18) Goldman, A. J., R. G. Cox and H. Brenner : Chem. Eng. Sci., 22, 653(1967)

19) Kirkland, J. J. and W. W. Yau : Science, 218, 121(1982) 